\title{
An Analysis of Technologies and Standards for Designing Smart Manufacturing Systems
}

\author{
SangSu Choi ${ }^{1}$, Kiwook Jung ${ }^{2}$, Boonserm Kulvatunyou ${ }^{3}$, and KC Morris ${ }^{3}$ \\ ${ }^{1}$ IGI, LLC \\ Clarksburg, MD, USA 20871 \\ ${ }^{2}$ Materials\&Production Engineering Research Institute, LG Electronics Inc. \\ 222 LG-ro, Jinwi-myeon, Pyeongtaek-si, Gyeonggi-do, 17709, South Korea \\ ${ }^{3}$ National Institute of Standards and Technology, \\ Gaithersburg, MD, USA 20899 \\ sangsu.choi@igiamerica.com \\ kiwook5.jung@lge.com \\ serm@nist.gov \\ kcm@nist.gov
}

Smart manufacturing is defined by high degrees of automation. Automation, in turn, is defined by clearly defined processes. The use of standards in this environment is not just commonplace, but essential to creating repeatable processes and reliable systems.

As with the rest of society, manufacturing systems are becoming more tightly connected through advances in information and communication technologies (ICT). As a result, manufacturers are able to receive information from their business partners and operational units much more quickly and are expected to respond quickly as well. Quick responses to changes in a manufacturing system are much more challenging than the responses that we have come to expect in other aspects of our lives.

Manufacturing revolves around heavy capital investments to rapidly produce large amounts of product in anticipation of steady streams of commerce. Changes under these conditions not only disrupt the operations, slowing the production of goods, but also create difficulties with managing the capital investments. These are challenges manufacturers face daily. A large part of these challenges is understanding how best to refit manufacturing facilities to respond to variability, and how to plan new production facilities. By analyzing the information that is available in a manufacturing system, manufacturers can make more informed decisions as to how to respond to change. Advances in the technological infrastructure underlying manufacturing systems are enabling more reliable and timely flow of information across all levels of the manufacturing operation. We propose that effective utilization of such operational information will enable more automated, agile responses to the changing conditions, i.e. Smart Manufacturing.

In this paper, we analyze the sources and the standards supporting the flow of that information throughout the enterprise. The analysis is based an intersection of two reference models: the Factory Design and Improvement (FDI) process and the ISA88 hierarchical model of manufacturing operations. The FDI process consists of a set of high-level activities for designing and improving manufacturing operations. The ISA88 hierarchical model specifies seven levels of control within a manufacturing enterprise.

Key words: Factory Design and Improvement (FDI); ISA-88; ISA-95; manufacturing software application; manufacturing system control; manufacturing system performance improvement; manufacturing system standard analysis; manufacturing workflow; re-engineering; production system planning; reference activity model; smart manufacturing system design.

Accepted: August 26, 2016

Published: September 20, 2016

http://dx.doi.org/10.6028/jres.121.021

\section{Introduction}

Several global organizations have reported on the dramatic changes that manufacturers will see as a result of emerging technological advances, calling the new breed of systems Smart Manufacturing Systems (SMS) [1-8]. Among those changes is the dynamic integration between business systems and services spanning manufacturing control levels $[9,10]$. These systems and services include PLM (Product Lifecycle 
Management), SCM (Supply Chain Management), ERP (Enterprise Resource Planning), and MES (Manufacturing Execution System), and devices. Lack of integration between these systems and services in operating factories often results in suboptimal benefits [11]. For instance, essential data have to be estimated because they cannot be acquired from dated equipment. Additionally, while particular processes can be improved by adopting automated machines, problems related to balancing whole production lines remain. At the same time, manufacturers are under greater pressure than ever before to produce a greater variety of products more quickly [12], resulting in a need to re-plan their factories. Manufacturing information systems contain a wealth of information that can help in this re-planning. In this paper, we analyze the scope of these systems and the standards that are available for accessing data from the systems in the context of how the data can be used for factory design and improvement. Particular focus is given to Digital Manufacturing (DM) tools as they are software tools that use integrated factory information for replanning the manufacturing systems. Their functionality typically includes simulating, visualizing, and analyzing a manufacturing system to simultaneously create production and manufacturing plan [13-15]. As such, DM tools are among the smart manufacturing enablers.

In previous work [16-19], a formal factory design process model, namely the Factory Design and Improvement (FDI) model, was shown to be a comprehensive method for designing a manufacturing system. In this paper, we use the FDI model to analyze manufacturing software tools and standards supporting the FDI. The result of the analysis can be used in constructing a new manufacturing system or enhancing an existing manufacturing system such that ICT enhancements can be implemented in a coordinated fashion to maximize their collective benefits. In addition, the analysis shows that DM tools are central to realizing an SMS. DM tools also need to be integrated among themselves and other supporting tools. Consequently, the manufacturing-focused standards critical to supporting integration are analyzed; and gaps and necessary enhancements are discussed.

The rest of the paper is structured as follows. In Sec. 2, we explain the concept of FDI. In Sec. 3, we present an analysis of technologies and standards supporting the FDI. First, the analysis scheme is constructed by establishing the relationship between FDI tasks and the ISA-88 manufacturing control architecture [20] in a functional matrix. Then, existing technologies and standards are explained and placed on the matrix. Finally, based on the analysis result, we discuss the development needs for standards to enable SMS. In the conclusion, we relate the analysis to future work.

\section{FDI Overview}

The FDI process is a comprehensive top-down planning and analysis process that covers physical design and software-system design of a manufacturing factory. It has been used successfully in an electromechanical component factory $[16,17]$. Such a comprehensive factory design process is important to ensure optimal overall system performance as it clearly indicates the dependencies and the needed interactions between its activities, subtasks, and stakeholders.

At a high-level, FDI consists of four activities as shown in Fig. 1, namely Develop Factory Requirement, Develop Basic Design, Develop Detailed Design, and Test. The figure also shows that the FDI activities impact the design of a manufacturing system from the enterprise-control level down to the equipment-control level per the ISA-88 control architecture. See Sec. 3.1 for the overview and interpretation of ISA-88 in this paper. Furthermore, the results of the FDI activities are used for both production planning and production control— the two major operational activities for ensuring the performance of a manufacturing system.

The four activities shown in Fig. 1 are further broken down into 28 tasks. Activities 1, 2, and 3 include tasks for multiple stakeholders (including high-level management) to review the output from each activity and discuss and resolve design issues from their viewpoints. The description and output of each task are formally modeled and described in Jung et al. 2016 [18, 19]. As shown on the left of Fig. 1 each task is associated with a certain control level entailing the stakeholders, personnel, and coordination presented within that control level. 


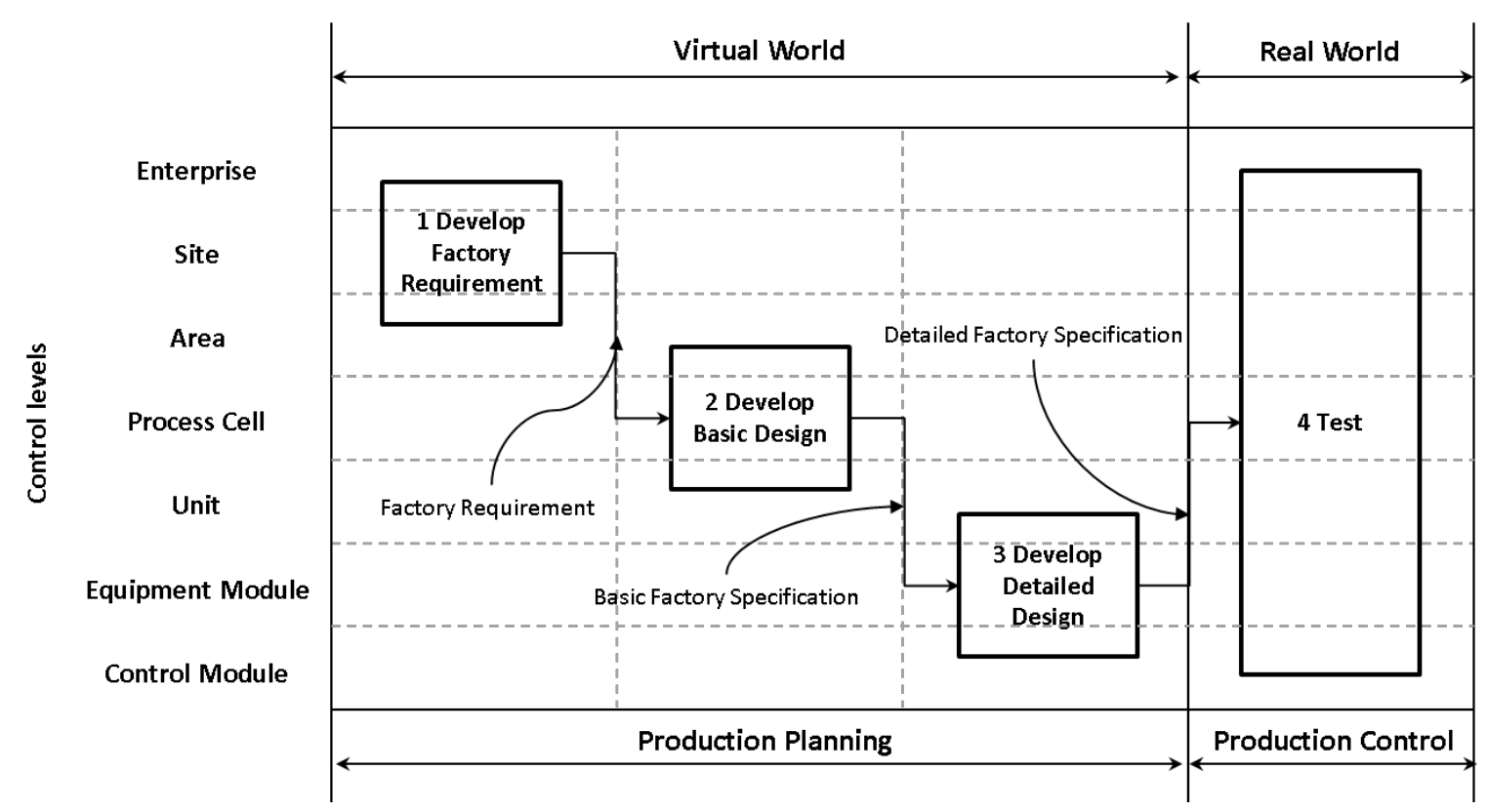

Fig. 1. Comprehensive Coverage of FDI approach.

\section{Analysis of Tools and Standards Supporting the FDI Process}

Since the FDI process spans multiple levels of control and different, yet overlapping, software tools feed data into DM tools used in these control levels, we analyze the software tools and standards supporting FDI in relation to the manufacturing control levels. The result of the analysis identifies overlapping relationships among these tools. We then analyze the standards based on these overlapping relationships.

\subsection{Method}

ANSI/ISA 88 contains a model and a methodology for the design and operation of a flexible production control system for batch processing. The ANSI/ISA 88 [20] control architecture ${ }^{1}$ has a hierarchy of seven levels, as shown in Fig. 2. Not all enterprises will have all these levels; therefore, the relations between the levels is represented as either "may contain" or "must contain." As shown on the right side of Fig. 2, an enterprise can have several sites. In other words, a manufacturing company can have several departmental organizations, each typically focusing on different sets of products. Each set of products may be produced in various facilities, i.e., actual factories (Areas in the ISA-88 model). Process Cell, Unit, Equipment Module, and Control Module levels correspond to manufacturing line, process, equipment/labor, and equipment controller, respectively. FDI focuses on the design of the lower five levels: Area, Process Cell, Unit, Equipment Module, and Control Module while incorporating constraints from the systems at the higher levels.

\footnotetext{
${ }^{1}$ ANSI/ISA95 [59] and ISA88 are commonly-used, related standard models for integration between enterprise systems and production management systems. ANSI/ISA 88 contains a model and a methodology for the design and operation of a flexible production control system for batch processing. While not designed for discrete manufacturing, because its control architecture is more detailed than ISA 95, we apply it to discrete manufacturing with minor modifications to the terminology. The physical model of ISA-88 used in this paper is compatible with the equipment hierarchy of ISA-95 (see [31] which provides detailed comparison between two standards).
} 


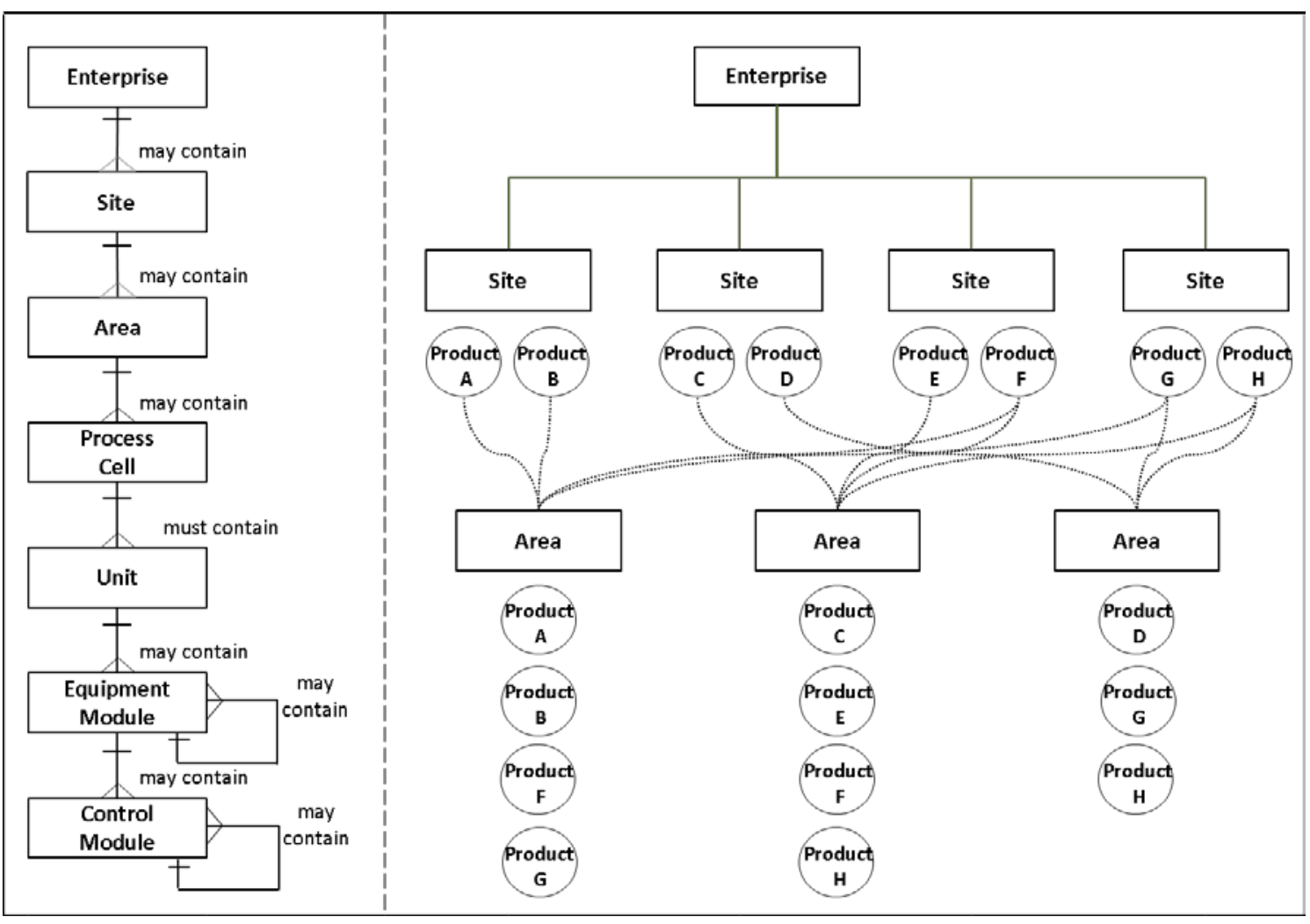

Fig. 2. ISA-88's physical model and an example production allocation.

The functional matrix shown in Fig. 3 illustrates that FDI tasks span all levels in the manufacturing control architecture. The dark grey boxes indicate at which control levels the different FDI tasks are performed. Tasks within the Develop Factory Requirement activity, in particular, are related to the Enterprise-, Site-, and Area-level control functions, while tasks within the Develop Basic Design activity are related mostly to the Process Cell and Unit-level control functions. The activity Develop Detailed Design takes the input from the basic design and goes deeper into the lower control levels. (Note that the numbers within each activity in Fig. 3 represent tasks within each activity, the details of which are documented in $[18,19]$. Both the basic design and detail design activities end with tasks that span multiple control levels to assemble the overall design. In the Test activity, a factory is constructed and all machines and ICT elements are installed and tested. Tasks in this activity involve fine tuning the design specification output from earlier activities and influence all the control levels.

\subsection{Analysis Result}

This section shows the results of the software tools and standards analysis. Tools and standards relevant to FDI are described and placed onto the functional matrix.

\subsubsection{Software Tools}

Scopes of software tools are typically different from vendor to vendor. For the purpose of our analysis, we define software categories and characterize them (provide their scopes) by specific functions. In this way, the analysis is clear and is independent from software vendor views.

Generally, ICT functions for manufacturing enterprises can be broadly categorized into ERP, SCM, PLM, MES, and DM application categories. Figure 4 shows where these software categories support the 


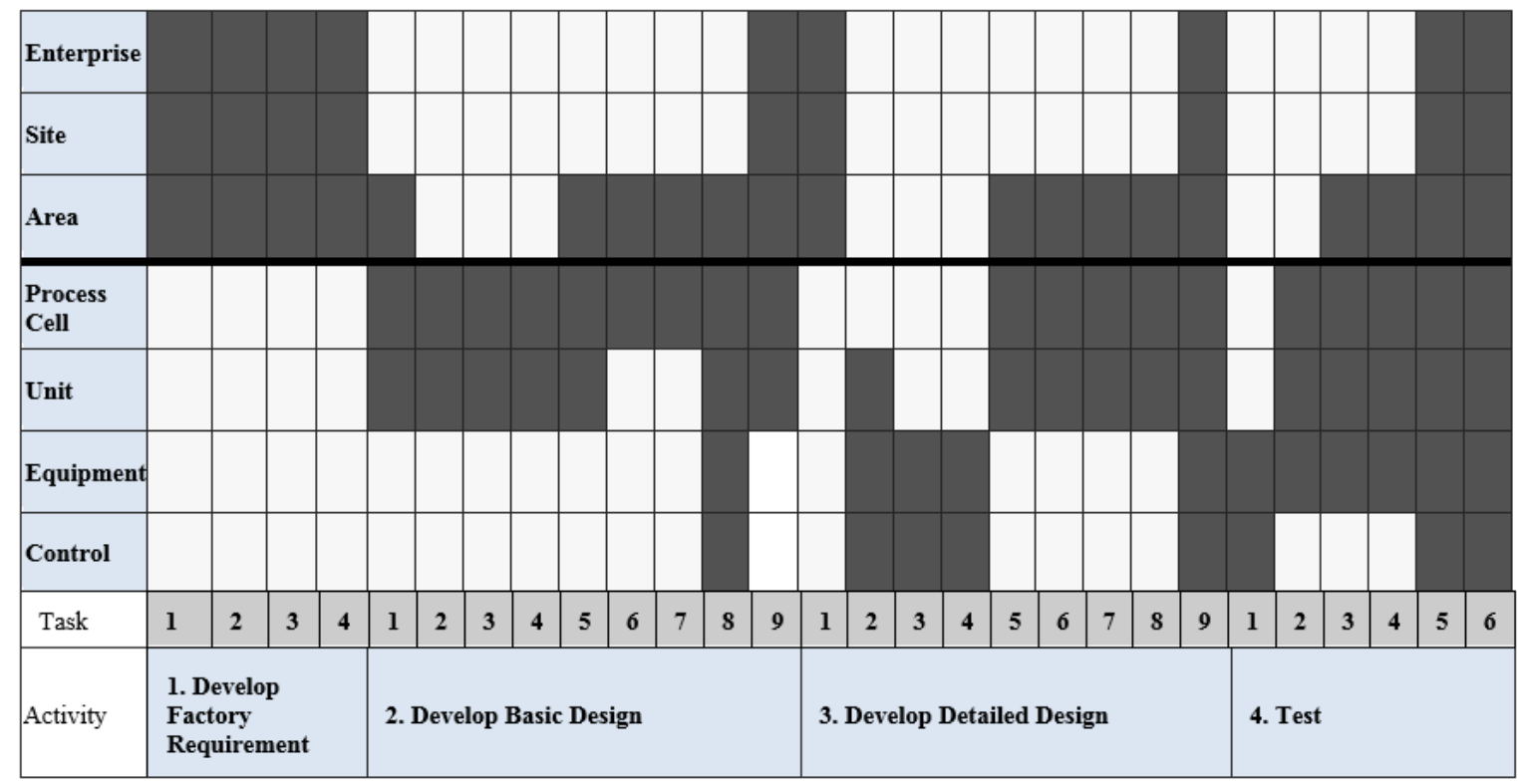

Fig. 3. A functional matrix mapping FDI activities onto manufacturing control levels.

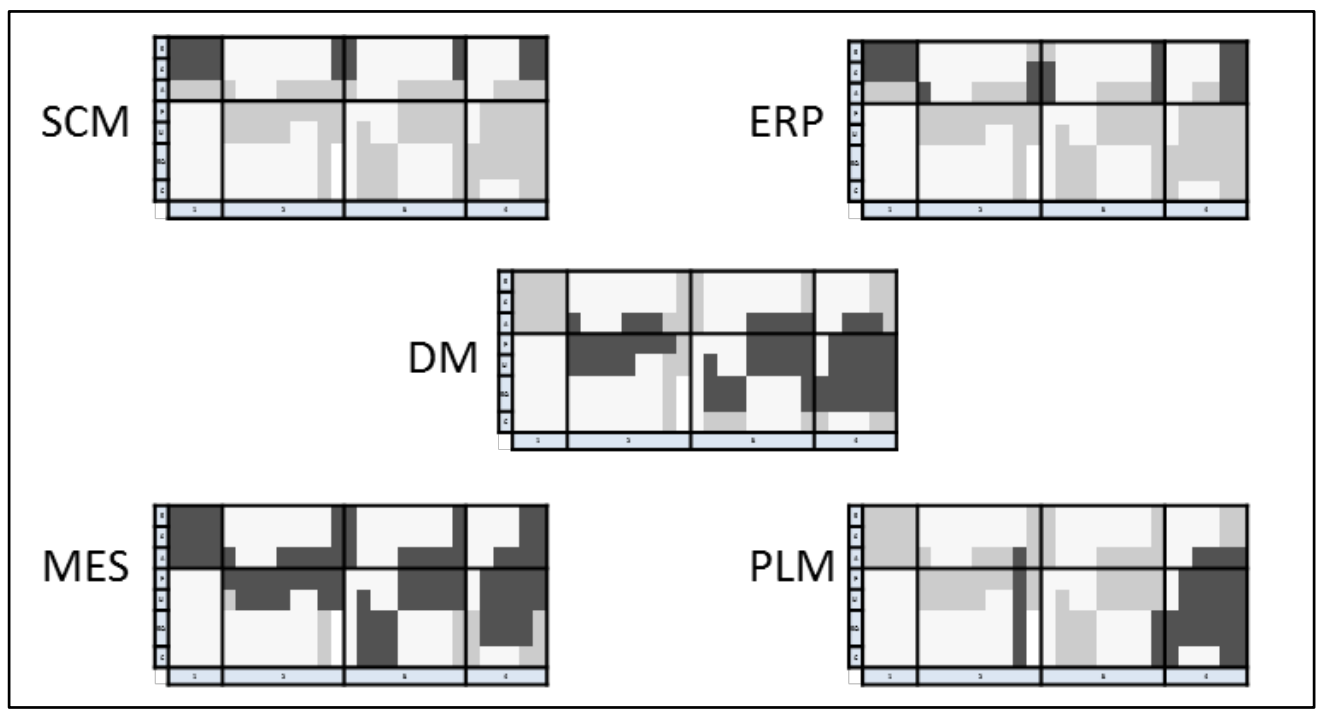

Fig. 4. Manufacturing software applied to the functional map.

FDI activities; and Table 1 indicates the specific functions covered in each of these categories. Electronic exchange of product, process, and production engineering information is required during both design and manufacturing [21]. DM tools [13, 14], in particular, are "the use of an integrated information for simulation, three-dimensional (3D) visualization, analytics, to create production and manufacturing plan simultaneously." [15] They allow for design and redesign of manufacturing systems to respond to changing situations represented by multi-criteria performance requirements and multiple environmental parameters and are the locus of FDI tasks. 
Table 1. Available FDI manufacturing software systems and their functions

\begin{tabular}{|l|l|}
\hline Application & Function \\
\hline PLM (Product Lifecycle Management) [22-26] & $\begin{array}{l}\text { Product design (CAx); Product and Portfolio Management (PPM); } \\
\text { Product Data Management (PDM); Manufacturing Process } \\
\text { Management (MPM) }\end{array}$ \\
\hline DM (Digital Manufacturing) [13-15] & $\begin{array}{l}\text { Tooling design and analysis; Assembly Line design and analysis; } \\
\text { Work Center design and analysis; Facility Layout design and } \\
\text { analysis; Ergonomics analysis; Resources management; } \\
\text { Production planning }\end{array}$ \\
\hline ERP (Enterprise Resource Planning) [27-30] & $\begin{array}{l}\text { Product planning; Cost/Pricing management; Project } \\
\text { management; Demand forecasting; Manufacturing or service } \\
\text { delivery management; Marketing and sales management; } \\
\text { Resource management; Inventory management } \\
\text { Financial management }\end{array}$ \\
\hline SCM (Supply Chain Management) [31-34] & $\begin{array}{l}\text { Inventory management; Distribution/Warehouse management; } \\
\text { Order Management; Procurement/Supplier management; } \\
\text { Transportation management; Shipping and payment management; } \\
\text { Customer relationship management; Supplier relationship } \\
\text { management } \\
\text { Channel management }\end{array}$ \\
\hline MES (Manufacturing Execution System) [35] & $\begin{array}{l}\text { Resource Allocation and Status; Operations/Detail Scheduling; } \\
\text { Dispatching Production Units; Document Control; Data } \\
\text { Collection/Acquisition; Labor Management; Quality } \\
\text { Management; Process Management } \\
\text { Maintenance Management; Product Tracking and Genealogy; } \\
\text { Performance Analysis }\end{array}$ \\
\hline & \\
\hline
\end{tabular}

Figure 5 shows the centrality of DM among other categories of tools. As can be seen, it provides inputs to, while at the same time requires inputs from, all other tools. DM allows a manufacturing enterprise's necessary data, including Product, Process, and Resource (PPR) data, to be shared and integrated with relevant business processes [36]. This centrality implies that integration points between DM tools and other categories of tools are essential to enable smart manufacturing. Standards are necessary to support these integration points to enable effective DM functions. We turn to that topic next.

\subsubsection{Standards}

We discuss standards from the perspective of the software tools described in the previous subsection focusing on the PPR standards necessary to enable DM functions. Table 2 summarizes these PPR standards. The standards are divided into three areas: product, process, and resource data. Product data standards cover the description of the product including its geometry and manufacturing specific constraints such as tolerances. Process data standards cover manufacturing instructions and reporting of operational results. Resource data standards cover the definitions and life-cycle information of the equipment and materials used in the production.

Table 2. Summary of standards relevant to enabling the PPR data exchange

\begin{tabular}{|l|l|}
\hline PPR Category & Standard \\
\hline Product data & $\begin{array}{l}\text { DXF, DWG, CGM, HPGL, IGES, STEP AP203, STEP AP214, JT, VRML, X3D, STEP AP239, AP242, } \\
\text { and the OMG PLM Services }\end{array}$ \\
\hline Process data & OAGIS, ANSI/ISA-95, MTConnect, PSL \\
\hline Resource data & CMSD, B2MML, STEP AP239, AP242, and the OMG PLM Services \\
\hline
\end{tabular}




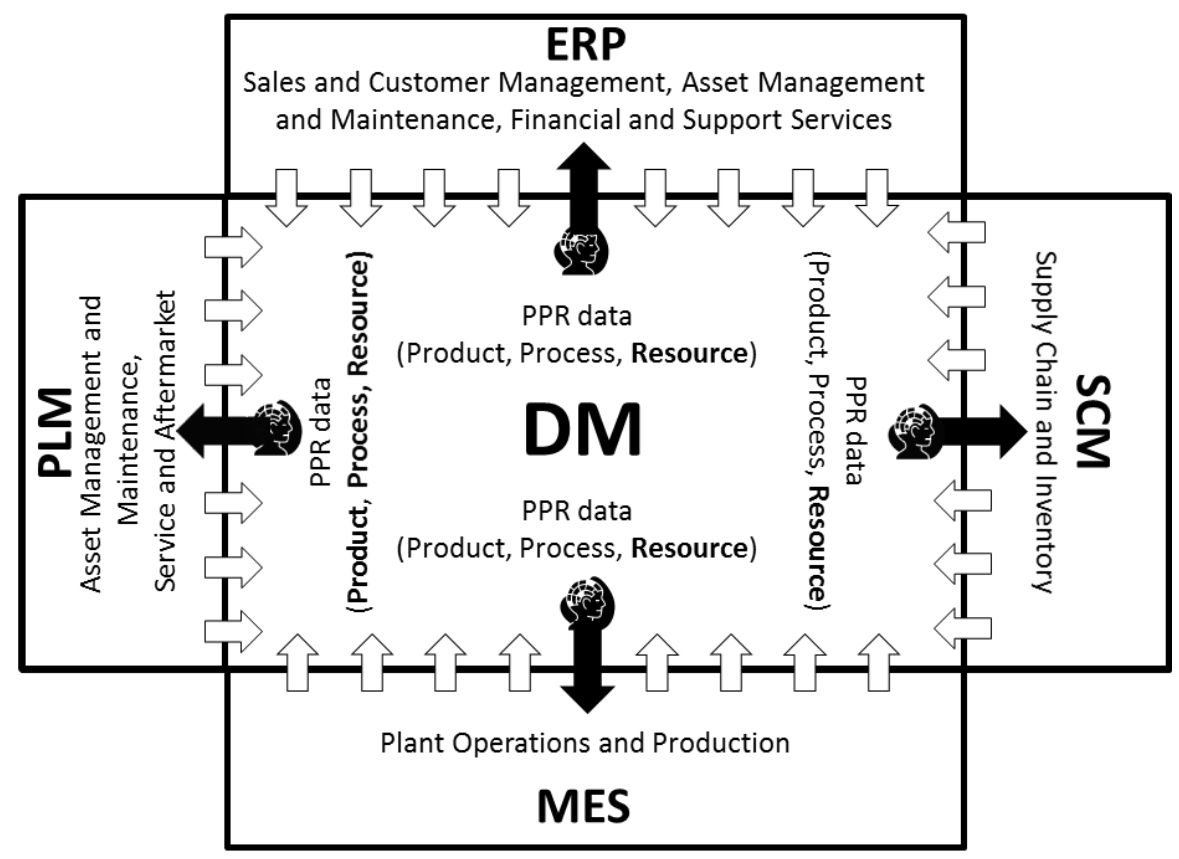

Fig. 5. DM tools as the focal point of SMS ICT applications.

For product data, a variety of CAx (Computer Aided tools)- and PLM-related standards exist. DXF [37] and DWG [38] are among the most popular two-dimensional CAD (Computer Aided Drawing) standards. Various vector image formats such as CGM (Computer Graphics Metafile) [39] and HPGL [40] are also widely used in work environments. IGES [41], STEP AP203 [42], STEP AP214 [43], and JT [44] are international standards for 3D data interchange, while VRML [45] and X3D [46] are frequently used for 3D data visualization. International standards related to PLM are, for example, STEP AP239 (commonly known as PLCS) [47], AP242 [48, 49], and the OMG PLM Services [50].

Process data standards are segmented by the manufacturing control levels. In the ERP and SCM areas, the Open Application Group Integration Specifications (OAGIS) [51], developed under the auspices of a number of ERP vendors, are representative of integration based on XML. In the MES area, there is the ANSI/ISA-95 enterprise-to-control-system integration standard. OAGIS is also widely used in discrete manufacturing for ERP and MES integrations. MTConnect [52] and OPC UA [53] are other standards in the MES area for collecting data from machine tools. The Process Specification Language (PSL) [54] is a standard for exchanging manufacturing process data between DM tools.

No specific standard represents resource data but several standards do cover different aspects of resource data. Core Manufacturing Simulation Data (CMSD) [55], a standard data model for interoperability between manufacturing simulation applications developed by the Simulation Interoperability Standards Organization (SISO) [56], covers data about manufacturing equipment as it relates to simulation. B2MML [57] supports modeling of equipment capability. Standards such as STEP AP239, AP242, and the OMG PLM Services provide some basic constructs covering engineering and lifecycle data for manufacturing equipment. Constructs in these standards can serve as a basis for integration of resource data and particularly the life-cycle aspects of that data. Further development and integration is needed in this area.

The core concepts defined in these standards provide the basis for a standard that allows for the efficient exchange of data required by DM tools. Research on information exchange models for product, process, and resource information that is essential for DM tools integration has been conducted by Choi et al. [36]. The results of this research can be used as a basis for DM standards that have yet to be developed. 


\subsubsection{FDI Software Tools and Standard Analysis}

Results of the FDI software tools and standards analysis in relationship to the FDI functional matrix are presented in this section. In Fig. 4 software tools are placed on the functional matrix to identify their use and functional overlaps. These overlaps indicate opportunities for standards to integrate information between these software tools. In the following subsection, we identify the relevant standards in these areas and highlight the standards gaps.

\subsubsection{Software Analysis}

The analysis shown in Fig. 4 illustrates in the coverage of the functions by the software categories discussed in Table 1. Dark shaded areas indicate where the manufacturing software categories apply to the FDI activities and control levels - the backdrop of the figure. The horizontal solid line in the middle of the matrix marks a functional divide between categories. Areas above the line have a concentration of ERP, SCM, and PLM functions in the Enterprise, Site, and Area control levels with much overlap between these software categories. The areas around and below the line show the DM, PLM, MES functions concentrated and overlapping significantly in the lower control levels. All the functional categories overlap in the Area and Process Cell levels. Overlapping functions are discussed below.

- Market forecasting: SCM has a customer relationship management (CRM) function that tracks customer behaviours associated with a product. The marketing and sales management function in an ERP should take CRM data into account for market forecasting. PLMs' portfolio management features rely on CRM data and also market-forecasting data. DM needs integration with PLM and SCM to share and exchange product data to analyze production feasibility based on market forecasts for a particular product.

- Cost Management: Cost, pricing, payment, and financial management functions in ERP are related to shipping-payment management-a function in SCM. PLM portfolio management functions also produce cost-estimation data. DM provides data required for cost estimation to PLM and vice-versa. Cost data should be integrated across these functions for comprehensive cost management. DM requires resource data from SCM and/or PLM for its resource-management function.

- Inventory Management: ERP and SCM have similar functions for inventory management; inventory information needs to be synchronized between these systems. DM provides functions to support verification of inventory management in ERP and SCM.

- Fulfilment Management: SCM has functions to manage distribution, transportation, channels, and suppliers, while ERP has functions for manufacturing- and/or service-delivery management. DM needs to be integrated with all these functions to provide supporting resource data. Having these functions and resource data accessible and integrated across the applications will facilitate customer order fulfilment. DM also supports verification of SCM distribution and transportation management.

- Project management: ERP project-management functions produce cost and schedule information for product or factory development. PLM product and portfolio management also has a projectmanagement function which adds finer-grain tasks and engineering data associated with those tasks. DM provides resource data associated with product and portfolio management. Projectmanagement information should be synchronized across the applications.

- Production planning: Both MES and DM have a function to make a production plan. These production planning functions should be consolidated. Alternatively, DM can be configured as an advanced planning system that provides necessary modifications to the MES plan in order to respond to the changing environment or more-complex performance requirements.

- Resource management: Resource (human, assets, and consumables) management functions in ERP, MES, PLM, and DM overlap. ERP and MES manage resource information related to the factory operation including real-time status. PLM also manages resource information, but focuses more on the life-cycle data such as maintenance history. The resource information in these applications need synchronization. DM tools need accurate and up-to-date resource information 
from both of these applications for accurate and timely production design. Therefore, resource information should be available for sharing across these applications.

\subsubsection{Standards Analysis}

Many existing standards support integration in the areas where the software functions overlap; however, these standards do not fully cover the functions and are not necessarily mutually compatible. Figure 6 overlays standards relevant to each area of the FDI activities on the functional matrix. Each dark grey oval indicates the coverage by a standard (or standards), while the lighter grey areas in which the ovals are placed indicate gaps. Sections with large areas of light grey indicate where substantial developments are needed.

The categories of software tools discussed earlier have also been overlaid in Fig. 6 which provides a holistic view across the standards, FDI activities, and software tools. More specifically, STEP AP239, AP242, PLM Services, and OAGIS standards are related to ERP, PLM, and SCM. These standards are mature but still growing in coverage. In addition, the ANSI/ISA-95 parts, which focus on the integration between ERP and MES, have existed since 2000 and vendor support is abundant. On the other hand, ISA95 parts for integration across MES systems themselves are just now being developed [58]. In the meantime, DM technologies are being adopted for factory optimization in manufacturing companies and need data from PLM. This may be supported by a combination of STEP AP239, AP242, PLM Services, PSL, and CMSD. However, no single coherent standard exists and there are still large gaps in coverage, as shown in Fig. 6. If these PLM and DM integration standards gaps are filled and are complemented with MES standards, DM tools will become more effective because the virtual (DM) tool can be connected with the operational tools (SCM, ERP, and MES) to obtain up-to-date information. Such connection is essential for making manufacturing systems more agile.

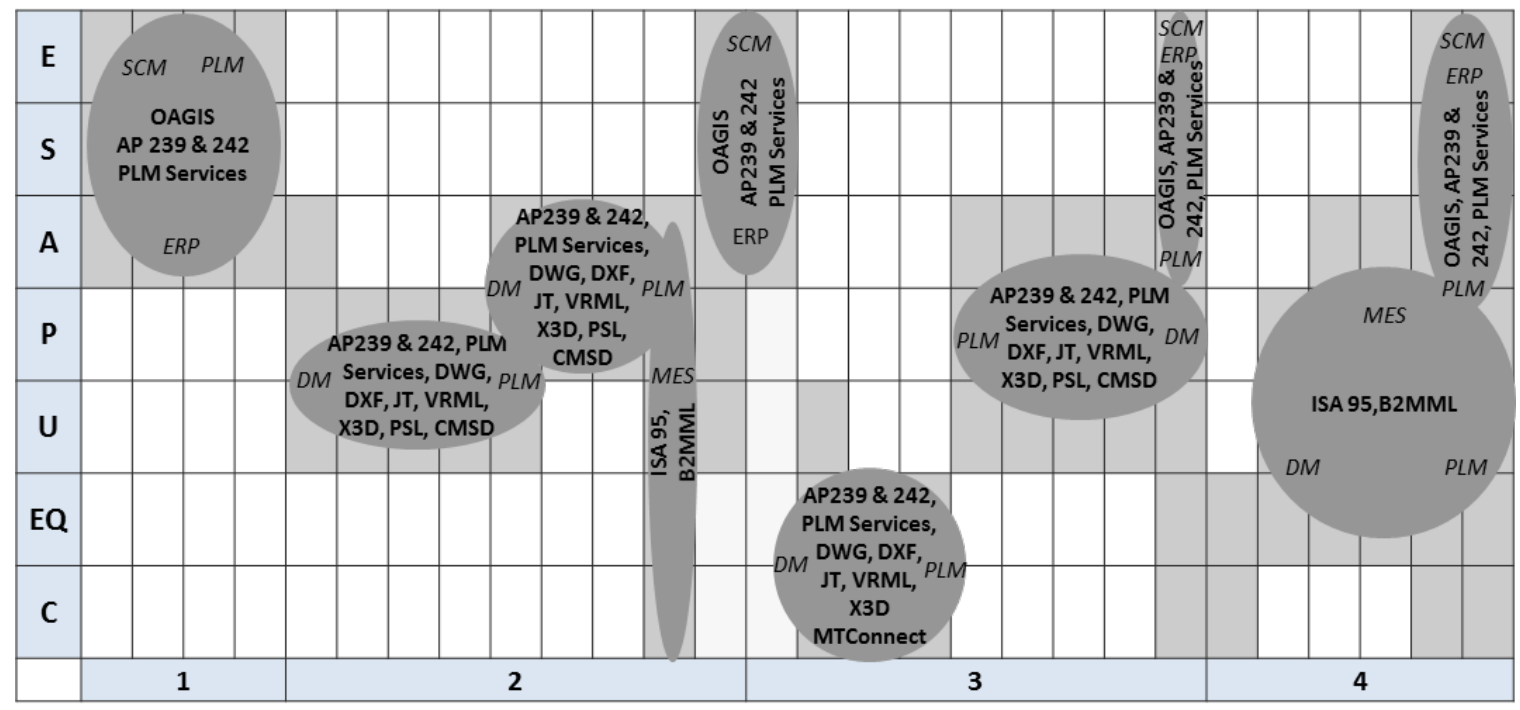

Fig. 6. Standard coverage on the FDI functional matrix.

\section{Conclusion and Future Work}

In this paper, we use the Factory Design and Improvement (FDI) process along with the ISA-88 manufacturing system control architecture to analyze software tools' functionalities, and standards necessary to enable an agile process for the design of a new factory or improvement of an existing one. The result of the analysis is two-fold. First, it shows that commercial off-the-shelf software tools are available 
for enhancing a manufacturing system. Manufacturing system engineers can use the results of the software tool and standard analysis from this paper along with the FDI process to plan for potential manufacturing system improvements, identify gaps in software tools and standards, and create plans to address or avoid those gaps. The second result of the analysis relates to the role of the DM tools. DM tools are the locus of FDI tasks because they allow the multitude of changes and disturbances to the manufacturing environment to be analyzed and corresponding adjustments to the manufacturing system to be planned. For DM tools to be effective, they must gather data from the run-time manufacturing control systems across all levels from the enterprise to equipment control. Therefore, interoperability between DM tools and other enterprise software tools is an important enabler for SMS. Data-exchange standards are needed to address this interoperability. The result of the standards analysis indicates a large gap in the areas related to PLM and DM software tools. This will be the focus of future work.

In order to develop DM-related standards, factory design activities from the Area to Equipment control levels have to be analyzed in more detail. Performance indicators associated with each activity will be needed. Both the activities and performance indicators drive the information requirements for DM-related standards, resulting in a comprehensive reference model for DM. Finally, working with tool vendors, we hope to identify suitable interfaces for standardization using the FDI and ISA reference models.

\section{References}

[1] Bauernhansl T (2013) Industry 4.0: Challenges and limitations in the production. Keynote; In: ATKearney, Factory of the year (Landsberg: Süddeutscher Verlag Veranstaltungen).

[2] Factories of the Future. Available at http://ec.europa.eu/research/industrial_technologies/factories-of-the-future_en.html. Accessed September 12, 2016.

[3] Global Agenda Council on the Future of Manufacturing (2014) The Future of Manufacturing: Driving Capabilities, Enabling Investments. Available at http://www.cggc.duke.edu/pdfs/Future_of_Manufacturing_Driving_Capabilities.pdf. Accessed March 14, 2015.

[4] Shipp S, Gupta N, Lal B, Scott J, Weber C, Finnin M, Blake M, Newsome S, Thomas S (2012) Emerging global trends in advanced manufacturing (Institute for Defense Analyses, Virginia, US).

[5] Smart Manufacturing. Available http://smartmanufacturing.com/what/. Accessed September 12, 2016.

[6] SMLC (2011) Implementing 21st Century Smart Manufacturing: Workshop Summary Report. Available http://www.energetics.com/resourcecenter/products/roadmaps/Documents/SMLC_Smart_Manufacturing.pdf. Accessed March 8, 2015.

[7] PCAST AMP Steering Committee (2014) Report - Accelerating U.S. Advanced Manufacturing.

[8] PCAST AMP Steering Committee (2014) Report - Accelerating U.S. Advanced Manufacturing, Annex 1-10: Transformative Manufacturing Technology.

[9] Jung K, Morris KC, Lyons KW, Leong S, Cho H (2015) Mapping Strategic Goals and Operational Performance Metrics for Smart Manufacturing Systems. Procedia Comput Sci 44:184-193. http://dx.doi.org/10.1016/j.procs.2015.03.051

[10] 28 Manufacturing Metrics that Actually Matter. Available http://blog.lnsresearch.com/blog/bid/188295/28-ManufacturingMetrics-that-Actually-Matter-The-Ones-We-Rely-On, Accessed March 14, 2015.

[11] MESA International (2013) Business Value of MES Study.

[12] MESA International (2014) 2013-2014 Manufacturing Metrics that Really Matter Summary Report.

[13] Chryssolouris G, Mavrikios D, Papakostas N, Mourtzis D, Michalos G, Georgoulias K (2009) Digital manufacturing: history, perspectives, and outlook. P I Mech Eng B-J Eng 223(5):451-462. http://dx.doi.org/10.1243/09544054JEM1241

[14] Delmia. Available at http://www.3ds.com/products-services/delmia/portfolio/delmia-v6/overview/. Accessed September 12, 2016/

[15] Digital Manufacturing. Available at http://www.plm.automation.siemens.com/en_us/plm/digital-manufacturing.shtml. Accessed September 12, 2016.

[16] Choi S, Hyeon J, Jang Y, Lee B, Park Y, Kang H, Jun C, Jung J, Noh SD (2014) The Integrated Design and Analysis of Manufacturing Lines (I) - an Automated Modeling \& Simulation System for Digital Virtual Manufacturing. Transactions of the Society of CAD/CAM Engineers 19(2):138-147. http://dx.doi.org/10.7315/cadcam.2014.138

[17] Choi S, Sung N, Shin Y, Noh SD (2014) The Integrated Design and Analysis of Manufacturing Lines (II) - Continuous Design, Analysis and Optimization through Digital Virtual Manufacturing. Transactions of the Society of CAD/CAM Engineers 19(2):148-156. http://dx.doi.org/10.7315/cadcam.2014.148

[18] Jung K, Choi S, Kulvatunyou S, Cho H, Morris K, A Reference Activity Model for Smart Factory Design and Improvement. Production Planning \& Control, in press.

[19] National Institute of Standards and Technology (2016) Factory Design and Improvement (FDI) Activity Model. Available http://www.nist.gov/el/msid/fdi.cfm. Accessed September 12, 2016.

[20] American National Standards Insitutue/International Society of Automation (2010) ANSI/ISA-88.00.01-2010 - Batch Control Part 1: Models and Terminology (The International Society of Automation, Research Triangle Park, NC).

[21] Kulvatunyou B, Ivezic N, Wysk RA, Jones A (2003) Integrated product and process data for business to business collaboration. Ai Edam 17(3):253-270. http://dx.doi.org/10.1017/S0890060403173076 
[22] Hill SJ (2003) How to be a Trendsetter: Dassault and IBM PLM Customers Swap Tales from the PLM Front. COE Newsnet.

[23] Karniel A, Reich Y (2011) Managing the Dynamics of New Product Development Processes: A New Product Lifecycle Management Paradigm (Springer London).

[24] Samuel SM, Weeks ED, Kelley MA, Design V (2006) Teamcenter engineering and product lifecycle management basics : a learning manual for teamcenter engineering with notes regarding implementation (Design Visionaries, San Jose, CA).

[25] Stark J (2011) Product lifecycle management (Springer London).

[26] Subrahmanian E, Rachuri S, Fenves SJ, Foufou S, Sriram RD (2005) Product lifecycle management support: a challenge in supporting product design and manufacturing in a networked economy. International Journal of Product Lifecycle Management 1(1):4-25. http://dx.doi.org/doi:10.1504/IJPLM.2005.007342

[27] Bidgoli H (2004) The Internet encyclopedia (John Wiley \& Sons, Hoboken, N.J.).

[28] Mabert VA, Soni A, Venkataramanan MA (2003) The impact of organization size on enterprise resource planning (ERP) implementations in the US manufacturing sector. Omega-Int J Manage S 31(3):235-246. http://dx.doi.org/10.1016/S03050483(03)00022-7

[29] SAP Enterprise Resource Planning. Available http://www.sap.com/pc/bp/erp/software/overview.html. Accessed September 12, 2016.

[30] Shaul L \& Tauber D (2012) CSFs along ERP life-cycle in SMEs: a field study. Ind Manage Data Syst 112(3-4):360-384. http://dx.doi.org/10.1108/02635571211210031

[31] Croom S, Romano P, Giannakis M (2000) Supply chain management: an analytical framework for critical literature review. European Journal of Purchasing \& Supply Management 6(1):67-83. http://dx.doi.org/http://dx.doi.org/10.1016/S09697012(99)00030-1

[32] Handfield RB, Nichols EL (1999) Introduction to Supply Chain Management (Prentice Hall, NJ).

[33] Lambert DM, Cooper MC, Pagh JD (1998) Supply Chain Management: Implementation Issues and Research Opportunities. The International Journal of Logistics Management 9(2):1-20. http://dx.doi.org/doi:10.1108/09574099810805807

[34] SAP Business Suite. Available http://www.sap.com/solution/lob/scm/software/overview/highlights.html. Accessed September 12, 2016.

[35] Muhammad Y, Cong P, Lu H, Fan Y (2010) MES development and significant applications in manufacturing -A review. In Proceedings of the 2nd International Conference on Education Technology and Computer, pp V5-97-V95-101. http://dx.doi.org/10.1109/ICETC.2010.5530040

[36] Choi SS, Yoon TH, Do Noh S (2010) XML-based neutral file and PLM integrator for PPR information exchange between heterogeneous PLM systems. Int J Comput Integ M 23(3):216-228. http://dx.doi.org/10.1080/09511920903443234

[37] Autodesk, Inc. (2007) AutoCAD 2008: DXF Reference (Autodesk, Inc., San Rafael, CA).

[38] Open Alliances (2013) Open Design Specification for .dwg files Version 5.3.

[39] WebCGM 2.1 (2010) W3C Recommendation, 1 March.

[40] Hewlett-Packard, and Hewlett-Packard Company (1997) The HP-GL/2 and HP RTL reference guide: a handbook for program developers. (Addison-Wesley Professional, MA).

[41] US Product Data Association (1996) Initial Graphics Exchange Specification. IGES 5.3 (American National Standards Institute).

[42] International Organization for Standardization (2011) ISO 10303-203:2011 - Industrial automation systems and integration -Product data representation and exchange -- Part 203: Application protocol: Configuration controlled 3D design of mechanical parts and assemblies (International Organization for Standardization, Geneva, Switzerland).

[43] International Organization for Standardization (2010) ISO 10303-214:2010 - Industrial automation systems and integration -Product data representation and exchange -- Part 214: Application protocol: Core data for automotive mechanical design processes (International Organization for Standardization, Geneva, Switzerland).

[44] Katzenbach A, Handschuh S, Vettermann S (2013) JT Format (ISO 14306) and AP 242 (ISO 10303): The Step to the Next Generation Collaborative Product Creation. Digital Product and Process Development Systems: IFIP TC 5 International Conference, NEW PROLAMAT 2013, Dresden, Germany, October 10-11, 2013 Proceedings, eds Kovács GL, Kochan D (Springer Berlin Heidelberg, Berlin, Heidelberg), pp 41-52.

[45] Ames AL, Nadeau DR, Moreland JL, Ames AL (1997) The VRML 2.0 sourcebook (Wiley, New York ; Chichester, Eng.) 2nd Ed, 654 p.

[46] Brutzman D, Daly L (2010) X3D: Extensible 3D Graphics for Web Authors (Morgan Kaufmann, Burlington, MA).

[47] International Organization for Standardization (2012) ISO 10303-239:2012 - Industrial automation systems and integration -Product data representation and exchange -- Part 239: Application protocol: Product life cycle support (International Organization for Standardization, Geneva, Switzerland).

[48] International Organization for Standardization (2014) ISO 10303-242:2014 - Industrial automation systems and integration -Product data representation and exchange -- Part 242: Application protocol: Managed model-based 3D engineering. Available http://www.ap242.org/. Accessed September 12, 2016.

[49] Feeney AB, Frechette SP, Srinivasan V (2015) A Portrait of an ISO STEP Tolerancing Standard as an Enabler of Smart Manufacturing Systems. J Comput Inf Sci Eng 15(2). http://dx.doi.org/10.1115/1.4029050

[50] Feltes M (2005) PLM Services-a standard to implement collaborative engineering (Daimler Chrysler Research).

[51] Open Applications Group. Available www.oagi.org. Accessed September 12, 2016.

[52] MTConnect ${ }^{\mathrm{TM}}$ (2008) Availble at www.mtconnect.org. Accessed September 12, 2016.

[53] OPC Foundation. OPC Unified Architecture Specification V. 1.0.

[54] International Organization for Standardization (2004) ISO 18629-1:2004 - Industrial automation systems and integration -Process specification language -- Part 1: Overview and basic principles (International Organization for Standardization, Geneva, Switzerland).

[55] Lee YTT, Riddick FH, Johansson BJI (2011) Core Manufacturing Simulation Data - a manufacturing simulation integration standard: overview and case studies. Int J Comput Integ M 24(8):689-709. http://dx.doi.org/10.1080/0951192X.2011.574154 . 
Leong S, Lee YT, Riddick F (2006) A Core Manufacturing Simulation Data Information Model for Manufacturing Applications. In Proceedings of the Simulation Interoperability Standards Organization Fall 2008 SIW Workshop (Orlando FL: Simulation Interoperability Standards Organization).

[56] Simulation Interoperability Standards Organization (SISO). SISO Policies and Procedures. Available http://www.sisostds.org/. Accessed September 12, 2016.

[57] MESA International (2008) Business to manufacturing markup language V0401.

[58] Scholten B (2007) The road to integration : a guide to applying the ISA-95 standard in manufacturing (ISA, Research Triangle Park NC).

[59] American National Standards Insitutue/International Society of Automation (2000) ANSI/ISA-95.00.01-2000 - EnterpriseControl System Integration Part 1: Models and Terminology (The International Society of Automation, Research Triangle Park, NC).

About the authors: SangSu Choi, Ph.D. is the CEO of IGI, LLC. He was a senior researcher at Samsung Electro-Mechanics and Siemens Industry Software and a guest researcher at the National Institute of Standards and Technology (NIST). His main interest lies in Smart Manufacturing Systems development and evaluation based on reference models.

Kiwook Jung Ph.D. is a senior research engineer at the Production-based Technology Department at the LG Production Research Engineering Institute. Before joining LG, he worked at the NIST as a guest researcher from Pohang University of Science and Technology. His research interests include developing manufacturing reference models and reference model-based evaluation methods in the context of Smart Manufacturing System.

Boonserm (Serm) Kulvatunyou, Ph.D. is a research scientist in the Systems Integration Division at NIST. Before joining NIST, he was a standards architect at Oracle Corp. His main interest is in enabling more efficient and effective systems integration.

KC Morris is the Information Modeling and Testing Group Leader in the Systems Integration Division at NIST and associate manager for the Design and Analysis of Smart Manufacturing Sytsems program. Her research interests include data and knowledge integration, manufacturing systems engineering, and sustainable manufacturing.

The National Institute of Standards and Technology is an agency of the U.S. Department of Commerce. 